International Journal on Design and Manufacturing Technologies, Vol.3, No.1, January 2009

\title{
STRUCTURAL PERFORMANCE OF BURIED FLEXIBLE PLASTIC PIPE - AN EXPERIMENTAL STUDY \\ Rajkumar R. ${ }^{1}$, llamparuthi $\mathrm{K}^{2}$ \\ ${ }^{1}$ Research Scholar, Department of Civil Engineering, Anna University, Chennai, India \\ ${ }^{2}$ Department of Civil Engineering, Anna University, Chennai, India \\ Email: 1rajpoor30@yahoo.com
}

\begin{abstract}
Buried pipes are used mainly for water supply and drainage besides many other applications such as pipelines for oil etc. They are manufactured from different materials in various shapes and sizes and are subjected to live loads and gravity loads. This paper deals with the experimental investigation conducted on flexible PVC pipes buried in loose and dense conditions of sand bed and subjected to surface pressures. The response of the pipes was studied with and without geogrid reinforcement. It was observed that the incorporation of geogrid reinforcement resulted in significant decrease in the crown deflection of the pipe and offered better protection to the pipe at shallow burial depths.
\end{abstract}

Key words: PVC pipe, Geogrid, Crown deflection, FEM, PLAXIS

\section{INTRODUCTION}

Pipes are important lifelines of modern urban infrastructure. Buried pipes are used mainly for water supply and drainage besides many other applications such as transportation of energy and mineral resources such as oil, liquefied natural gas, coal slurries and mine tailings. The pipes may be rigid or flexible although the distinction between the two categories is blurring. The design of flexible pipes is controlled by deflection or elastic buckling. In fact with good quality backfill buckling is usually not a concern and deflection controls the design (Duncan 1979).

Materials technology has evolved the most among all aspects of pipelines engineering. Many new materials such as plastic resins appeared on the market. There are three main types of plastic pipes used in water-industry applications. They are Polyethylene (PE), Polyvinyl chloride (PVC), and Fibre-reinforced plastic (FRP).

PVC is a thermoplastic and it is stronger than polyethylene, allowing thinner sections and reducing both weight and cost. The popularity of plastic pipes is due to constant improvements being made in manufacturing technologies and advantages over the conventional concrete and ductile iron pipes in terms of light-weightness, cost efficiency and long term chemical stability.

Considerable work has been done to study the response of buried pipe analytically (using elastic theory) and numerically (using approximate methods such as finite element and finite difference techniques) by Burns (1974), Hoeg (1968), Abel (1973), Anand(1967), Katona(1976), Ramakrishnan(1979), Valliapan(1977). However experimental work in the area of buried pipes has not received much attention from research workers.

Marino and Riley (1964) studied response of structural models subjected static and dynamic over pressures experimentally. The models were studied for different diameter to thickness ratios and for influence of end closure systems. It was observed that increase in soil overpressures has significant influence on the hoop bending of cylindrical shell and with increase in flexural rigidity of cylinder; the model deformation was less under the load. Allgood (1964) and Luscher and Hoeg (1965) also studied response of buried pipe experimentally.

Sivakumar Babu et.al presented a critical appraisal of the mechanical behaviour of buried flexible pipes and proposed design methodology for prediction of performance of buried flexible pipes using finite element analysis. A design chart for the analysis of a pipe section in terms of deflection and buckling was presented.

Zhan and Rajani carried out a non linear finite element analysis to assess the effects of different trench backfill materials, pipe burial depths and pipe materials on the amount of traffic load transferred to the buried pipe. The analysis showed that the use of trench backfills such as controlled low strength material (CLSM) instead of traditional materials such as sand and clay resulted in significantly reduced stresses in PVC pipes under traffic loading conditions.

This paper explores the design of flexible plastic PVC pipe, buried in shallow trench conditions with dry sand backfill and subjected to static loading. Primarily the study reported here is an attempt to understand the complex soil-structure interaction between the pipe and soil. The tests were conducted on PVC pipes of $200 \mathrm{~mm}$ diameter. The objective of the tests was to provide guidelines to minimise the deformations on buried pipes under static loading conditions. The experimental results so obtained were compared with 2D finite element analyses conducted on buried pipe installations using 'PLAXIS'. 


\section{PROPERTIES OF SOIL AND PIPE MATERIAL}

A. Soil

Poorly graded sand adopting controlled pouring, tamping and vibration techniques was used in all the experiments. A homogenous sandbed and reproducible density was maintained throughout the test. All the experiments were conducted with soil in air dry state. For cohesionless soils relative density gives a useful measure of compaction and its values are obtained as per IS2720 partXIV.

\section{B.Pipe}

PVC pipe of $200 \mathrm{~mm}$ diameter and thickness $5 \mathrm{~mm}$ was used in the experimental study. The structural properties of the pipe were in part given by the pipe manufacturers and tallied closely with those given in literature.

\section{Geogrid}

A geogrid is a section of specified dimensions consisting of bars of some size intersecting at right angles. Grids are similar to welded wire fabric except that usually the grid rods in one direction do not lie on top of the rods in the orthogonal direction.

The geogrid effectively increase the angle of internal friction and cohesion and are used to improve the bearing capacity and spread the loaded area. Geogrid carry substantial tensile stresses and tend to deform considerably under relatively small stresses.

The different properties of the materials thus obtained and used in the computations are tabulated below:

Table 1. Properties of Material

\begin{tabular}{|c|c|c|c|c|c|}
\hline Properties & Loose Sand & $\begin{array}{l}\text { Dense } \\
\text { Sand }\end{array}$ & PVC & $\begin{array}{l}\text { Steel } \\
\text { Plate }\end{array}$ & $\begin{array}{l}\text { Netlon } \\
\text { GeoGrid }\end{array}$ \\
\hline $\begin{array}{l}y \\
(\mathrm{kN} / \mathrm{m} 3)\end{array}$ & 15 & 17 & $\cdot$ & & $\cdot$ \\
\hline $\begin{array}{l}\mathrm{E} \\
(\mathrm{KN} / \mathrm{m} 2)\end{array}$ & 9000 & 19000 & $0.933 \mathrm{E}+06$ & & $\cdot$ \\
\hline v & 0.30 & 0.30 & 0.31 & 0.30 & $\cdot$ \\
\hline $\begin{array}{l}\text { EA } \\
(\mathrm{K} N \mathrm{~m})\end{array}$ & & & 4665.00 & $24 E+06$ & $\infty$ \\
\hline $\begin{array}{l}\text { 日 } \\
(\mathrm{K} / \mathrm{N} \mathrm{R} / \mathrm{m})\end{array}$ & & & $9.7 \mathrm{E}-03$ & 28.8 & \\
\hline $\begin{array}{l}\$ \\
\text { (degrees) }\end{array}$ & 32 & 42 & $\cdot$ & & - \\
\hline$\Psi$ (degrees) & 2 & 12 & - & & . \\
\hline
\end{tabular}

\section{EXPERIMENTAL INVESTIGATION}

The prime objective of the investigation is to study the behaviour of Plastic pipe embedded in dry cohesion less medium subjected to compression loads with and without geogrids. PVC pipe was buried in loose and dense conditions of sand bed and their response was studied for different backfill covers. Various important parameters considered are crown deflection of the pipe, surface pressure, modulus of the pipe and soil, depth of embedment, diameter and thickness of the pipe, Poisson's ratio of the pipe and angle of internal friction and relative density of the soil.

\section{EXPERIMENTAL SETUP AND TESTING PROCEDURE}

The experimental research program consisted of two distinct categories of tests. In the first series of experiments the deformations on the pipe were studied in the absence of geogrid reinforcement. In the second series geogrid reinforcement (Netlon geogrid 121) was used to enhance the performance of the pipe.

A fabricated M.S.tank of size $0.6 \mathrm{~m} \times 0.6 \mathrm{~m} \times 1.2 \mathrm{~m}$ was used to study the response of buried PVC pipe. A load frame of $50 \mathrm{KN}$ capacity was used to transfer the load on the buried pipe. A mild steel plate of size $200 \mathrm{~mm} \times 600 \mathrm{~mm} \times 12 \mathrm{~mm}$ was used for transferring the load uniformly from the plunger. To measure the load, a Proving ring which connected to the plunger was used. The rate of loading for all the experiments was kept constant.

PVC pipe of $200 \mathrm{~mm}$ diameter was tested for varying backfill covers of loose and dense sand beds. Deflections of selected pipe cross sections were recorded during loading of the surface of the backfill. The settlement of the loading plate was also monitored using two dial gauges. In the second series of experiments geogrid was placed at $200 \mathrm{~mm}$ above the pipe crown and the vertical and horizontal deformations of the pipe were recorded using the deflectometers. An overall view of the testing arrangement is shown in the fig 1 . 


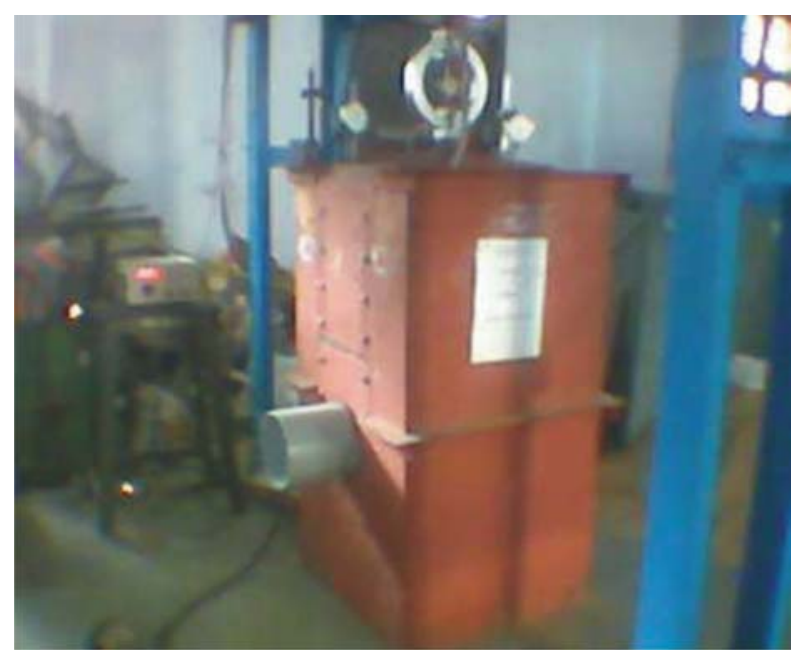

Fig. 1. Overall view of the experimental facility

\section{FINITE ELEMENT MODEL}

The finite element analysis was performed to model the response of the buried flexible plastic pipes in different backfills, embedded at different levels and compare the behaviour with the experimentally obtained results. Finite element analysis program 'PLAXIS' was used to study the interaction of PVC pipes with the backfill soil. The cross trench condition was analysed as a plane strain condition. The pipe used in the analysis has a diameter of $0.2 \mathrm{~m}$ and wall thickness of $5 \mathrm{~mm}$. To exactly simulate the experimental model the right hand boundary was selected at 1.5D away from the trench center with a restricted horizontal displacement and free vertical displacement. The bottom boundary was located at $1.2 \mathrm{~m}$ below the surface with a restricted vertical displacement and free horizontal displacement. Six

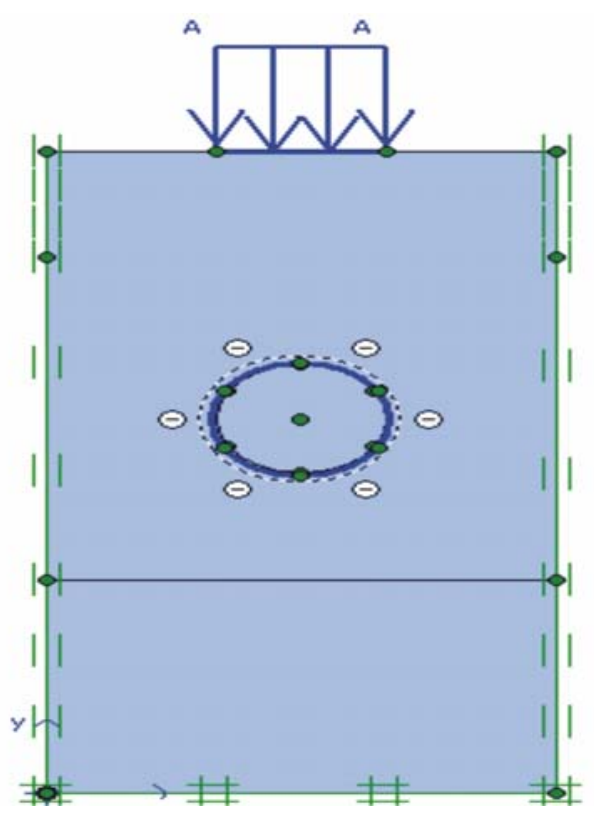

Fig. 2. Plot of geometry model with boundary conditions circular segment elements were used to represent the pipe. Fifteen noded plane strain triangular elements were used to model the backfill. The numerically simulated model is as shown in the fig. 2

\section{RESULTS AND DISCUSSION}

The diametric strain of the pipe both vertically and horizontally has been plotted against the surface pressure under various levels of backfill cover as shown in fig 3 and 4 .

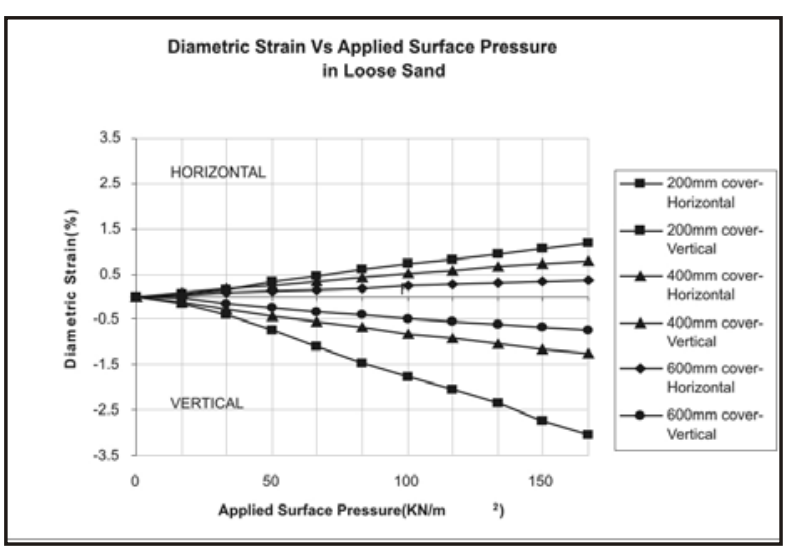

Fig. 3. Deflection response to loading of $200 \mathrm{~mm}$ diameter pipe with varying backfill covers in loose sand

The upper half of the diagram consists of positive diametric strains or extensions of the pipe at the springing line. The lower half consists of negative diametric strains or compression at the crown of the pipe. The pipe response to the applied pressure is almost linear leading to an elliptical deformation.

The pipe deformations were quite localised. The greatest reduction in diameter occurred vertically under the centre of the loading plate. The pipe crown deflected most directly beneath the centre of the loading plate. The invert of the pipe suffered little movement but tended to rise slightly well away from the loaded area.

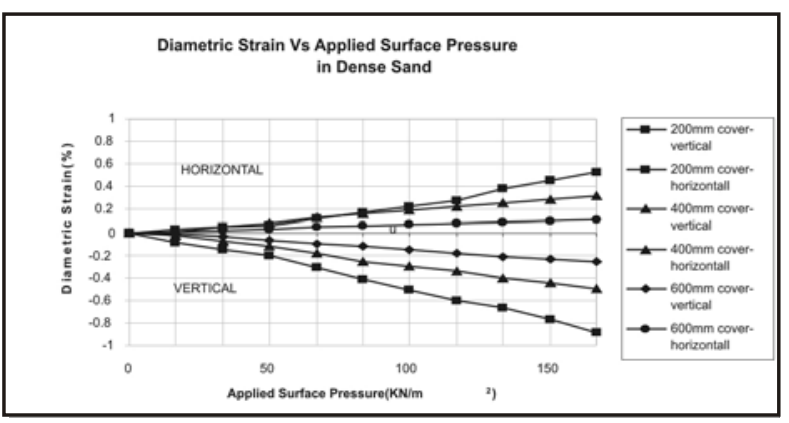

Fig. 4. Deflection response to loading of $200 \mathrm{~mm}$ diameter pipe with varying backfill cover in Dense sand 
It can be seen in the plots of the pipe strain with applied pressure that the vertical diametric strain was usually significantly higher than the horizontal strain.

Excessive ratios of vertical to horizontal strain indicate the local buckling failure of the pipe crown. With greater load and deflection, the deformation ratio increased as the vertical diameter strain increased to $3 \%$. So the pipe deformation becomes less elliptical as the vertical deformation increased.

The deformation response of the pipe soil system to the external loading was non linear. The pipes were usually observed to regain their shapes after they were recovered from the buried pipe installation. It is evident from the results that increasing the backfill cover afforded greater protection to the pipe. A comparison of load deflection data for $200 \mathrm{~mm}$ and $600 \mathrm{~mm}$ cover verifies that cover height is an important parameter in limiting pipe deflection for a given load. At the shallow cover height of the backfill loads were transmitted directly to the crown of the pipe as the loading plate has not penetrated the sand at their small pressure. As the cover height increased the stiffness of the soil pipe system increased.

It is evident from fig. 5 that the load coming over the pipe dramatically reduced in the presence of geogrid reinforcement placed at $200 \mathrm{~mm}$ above the pipe crown. From the figure it is clear that the vertical diametric strain reduced by $25 \%$ at a surface pressure of $100 \mathrm{Kpa}$ for the shallow cover with geogrid reinforcement and further reduction was observed with the increase in surface pressure. This shows that the presence of geogrid reinforcement offers greater protection for pipes buried in shallow covers and hence the need for deep burial could be minimised.

The variation of ${ }^{a}$, with respect to P/ãd been presented in figure 6 for $200 \mathrm{~mm}$ diameter pipe in loose sand condition with and without geogrid reinforcement. The following trends can be observed from the figures. The variation of ${ }^{a}$ with P/ãd can be seen to be linear at the crown . The above graph originate from near the origin (but not passing through the origin probably because of soil confining pressure. The Strain values were considerably reduced when a single layer of geogrid reinforcement was placed at $200 \mathrm{~mm}$ above the pipe crown and the maximum reduction was observed when two layers of geogrid reinforcement were placed at the springing line with dense packing of dry sand within the layers. The strain values were found to be more for loose sand than for the conditions of dense sand since the modulus in the former case was less than in the latter case.

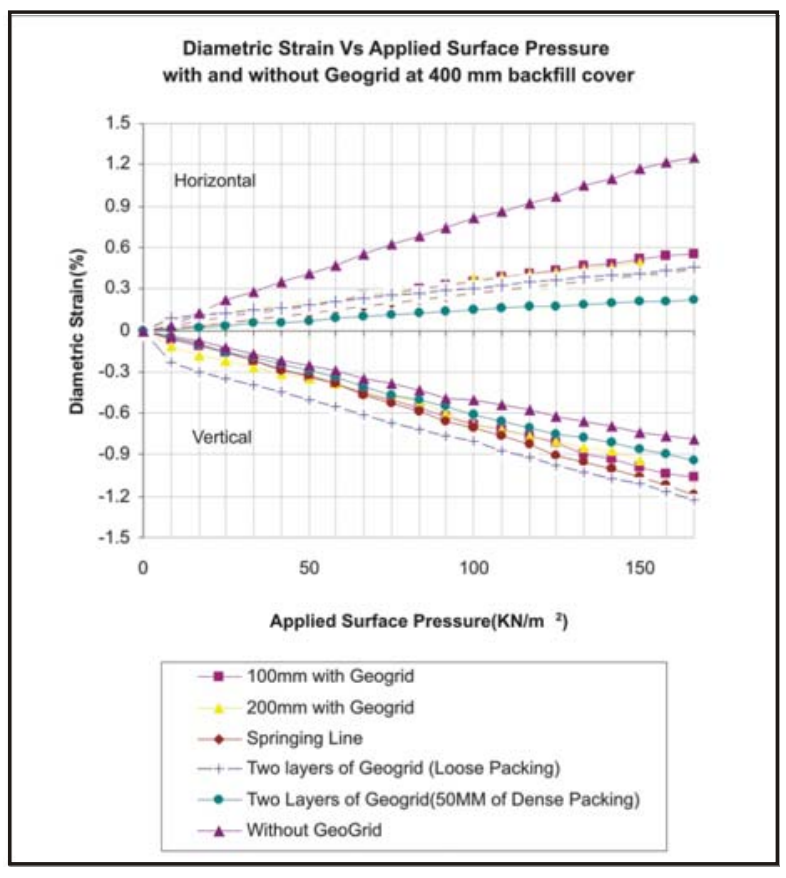

Fig. 5. Influence of geogrid reinforcement on the vertical and horizontal strain at $200 \mathrm{~mm}$ above the pipe crown (centre of the pipe)

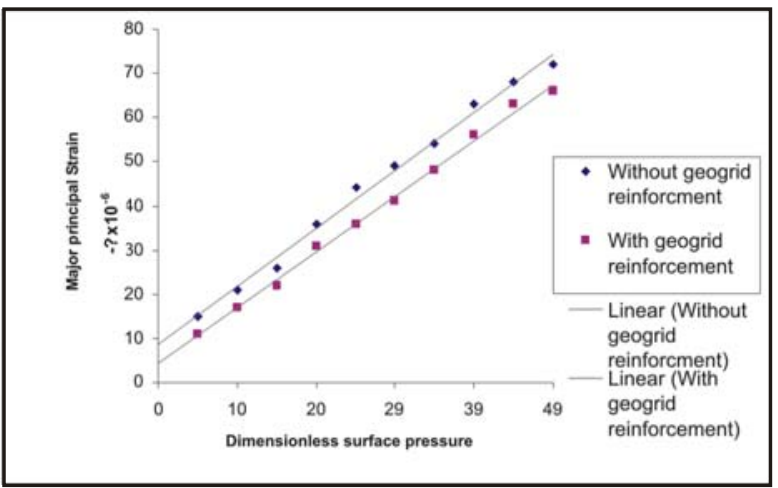

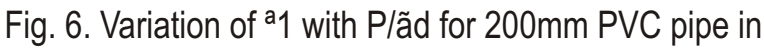
loose sand with $600 \mathrm{~mm}$ cov

\section{FINITE ELEMENT RESULTS}

The match with the experimental data was reasonably good owing to inadequacies of the 2D predictions involving assumption of a rigid side boundary. The walls of the laboratory test box may not have been perfectly rigid and this factor could have influenced the FEA predictions. The correspondence of the FEA output with the horizontal pipe strain was less satisfactory. It is also apparent that the two dimensional FEA predictions of pipe-soil system behaviour indicate an almost linear displacement of pipe deflection with applied pressure.In the figs 7 and 8 . The applied pressure and the corresponding crown deflection of the pipe are compared for $400 \mathrm{~mm}$ of backfill cover with and without geogrid 
reinforcement in dense and loose conditions of sand. The test observations indicated a noticeable difference in the vertical crown deflection of the pipe due to the applied surface pressure with the incorporation of geogrid reinforcement at $200 \mathrm{~mm}$ above the crown of the pipe.

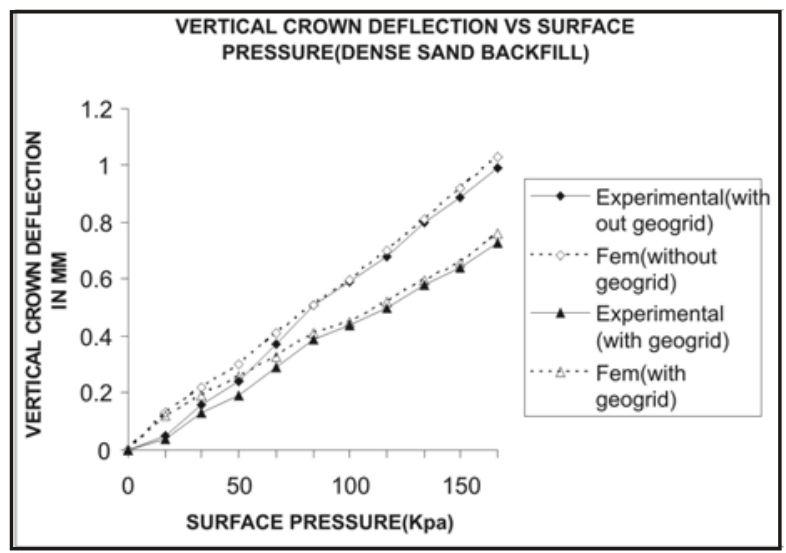

Fig. 7. Comparison of Experimental results with 2D finite element analyses for $400 \mathrm{~mm}$ cover with and without geogrid reinforcement in dense sand.

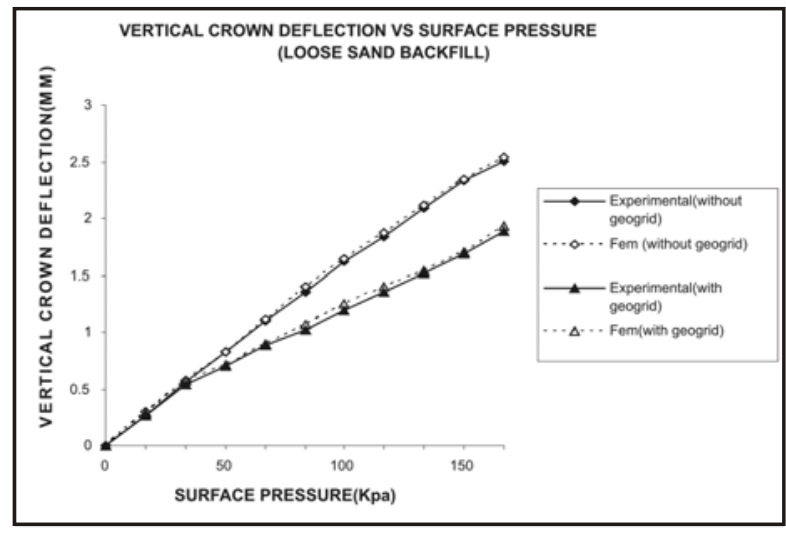

Fig. 8. Comparison of Experimental results with 2D finite element analyses for $400 \mathrm{~mm}$ cover with and without geogrid reinforcement in loose sand.

Contours of both vertical deflection and deviatoric stress are provided in figure 9 for FEA data near the end of the analysis for $200 \mathrm{~mm}$ diameter pipe with $400 \mathrm{~mm}$ cover.

The test observations indicated a noticeable difference in both the horizontal and vertical responses with loading .The FEA predictions were reasonably good for the vertical strains. The major principal stress was more at the edge of the loading plate and adjacent to the centre of the pipe. The stress concentration from the edge of the loading plate headed towards the quarter point of the pipe at $45^{\circ}$ from the pipe crown. The plots of the deviatoric stress show a more extensive but similar zone of high stresses which reaches the quarter point of the pipe.Such a pattern of stress development could be expected in soil which is conducive to arching. The crown of the pipe having deflected significantly has shed load to neighbouring pipe sections.
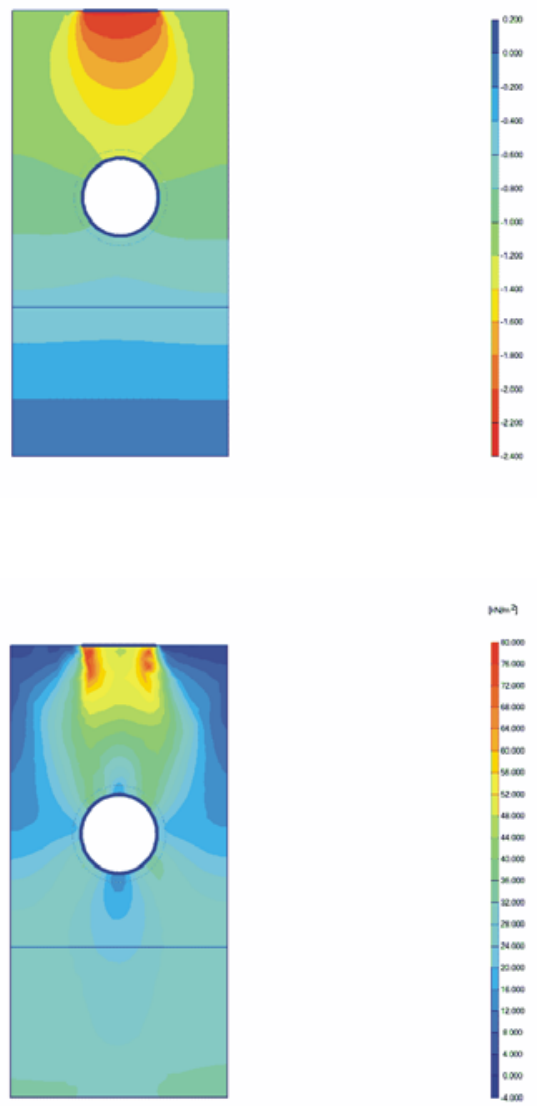

Fig. 9. Contours of 2D FEA data for test of $200 \mathrm{~mm}$ diameter pipe with $400 \mathrm{~mm}$ ofcover

It is evident that the use of geogrid reinforcement theoritically affords better protection for the pipe.Lateral pipe strains were similarly reduced.

The vertical displacement contours indicate the local settlement of the loading plate and the transfer of deflection through the backfill to the pipe crown.

\section{CONCLUSIONS}

The increase in cover height offered better protection to the buried flexible plastic pipe but this can be reduced with the presence of geogrid reinforcement. Two dimensional FEA could not adequately model the observed behaviour of the soil pipe systems and hence needs to be treated with caution. Crown deflection is more pronounced in the case of loose sand backfill than in the case of dense sand backfill. The strain values for loose sand are more than those for dense sand which can be expected since the modulus of the soil in the former case 
is less. Variation of hoop strain with dimensionless surface pressure is linear at the crown and the springing line.

The load carrying capacity of the pipe can be increased significantly by the use of geogrid reinforcement. The crown deflection of the pipe at any stage in reinforced soil is less than the deformation in unreinforced condition. Maximum decrease in the deformations and stresses was observed with the provision of double layer of geogrid reinforcement along the springing line with dense sand packing between the layers of reinforcement.

\section{REFERENCES}

[1] Jeyapalan,K and Boldon,B.A, 1986, "Performance and selection of Rigid and flexible pipes", Journal of transportation engineering,vol 112,No.5,paper No.20900 pp 507-523

[2] Zhan.C and Rajani .B, 1997, " Load transfer analysis of buried pipe in different Backfills," Journal of transportation engineering, vol.123, No.6 Paper No.13109, pp 447-453
[3] Sivakumar babu.G.L.,Renjith V.K,Seshagiri Rao.R and Srinivasa murthy B.R, 2003, "Finite Element analysis of buried flexible pipes", Indian Geotechnical journal 32(2), pp125-143

[4] Rajesh kataria and kameswara Rao, 1982, N.S.V, "Response of buried pipes to static overpressures," Indian geotechnical journal, pp 208-21

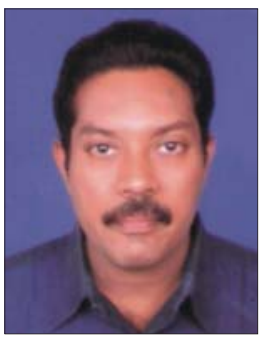

Mr. R.Rajkumar is a Research Scholar at the Faculty of Civil Engineering, Anna University, Chennai, and an Assistant Professor at the Department of Civil Engineering, Sathyabama University, Chennai. He has twelve years of teaching experience and has guided about 60 undergraduate and post graduate theses. He has published twenty three technical papers in the International and National Journals and Conferences. 